\title{
Crystal and Molecular Structure, and Spectral Characteristics of Sodium 3,5-Bis(Hydroxyimino)-1-Methyl-2,4,6- Trioxocyclohexanide
}

\author{
Olga Kovalchukova ${ }^{1}$, Nguyen Dinh Do ${ }^{1}$, Adam Stash², Vitaly Bel'sky ${ }^{2}$, Paul Strashnov', \\ Andrew Alafinov ${ }^{3}$, Oleg Volyansky ${ }^{3}$, Svetlana Strashnova ${ }^{1}$, Konstantin Kobrakov ${ }^{3}$ \\ ${ }^{1}$ Department of General Chemistry, Peoples' Friendship University of Russia, Moscow, Russia \\ ${ }^{2}$ Karpov Institute of Physical Chemistry, Moscow, Russia \\ ${ }^{3}$ Department of Organic Chemistry and Chemistry of Dyes, Moscow State Textile University, Moscow, Russia \\ Email: okovalchukova@mail.ru
}

Received September 26, 2012; revised November 1, 2012; accepted November 12, 2012

\begin{abstract}
Sodium 3,5-bis(hydroxyimino)-1-methyl-2,4,6-trioxocyclohexanide $\mathrm{C}_{7} \mathrm{H}_{5} \mathrm{~N}_{2} \mathrm{NaO}_{5}$ (I) has been isolated as the only product of the reaction of nitrosation of methylphloroglucinol. The structure of the titled compound has been determined from single crystal X-ray diffraction data. The hydrated $\mathrm{C}_{7} \mathrm{H}_{5} \mathrm{~N}_{2} \mathrm{NaO}_{5} \cdot 2.5 \mathrm{H}_{2} \mathrm{O}$ crystallizes in the monoclinic space group C2/c, with a $(\AA)$ 16.408(3); b $(\AA)$ 12.446(3); c $(\AA)$ 13.716(3); $\beta\left(^{\circ}\right)$ 126.34(3). The planar organic anion exists in a triketo-dihydroxyimino form with the $\mathrm{C}-\mathrm{O}$ and $\mathrm{C}-\mathrm{N}$ distances from 1.220(2) to 1.271(2) $\AA$ and from 1.292(2) to $1.293 \AA$ respectively. In the IR spectrum of I, the sharp absorption band occurred at $1681 \mathrm{~cm}^{-1}$ due to $\mathrm{C}=\mathrm{O}$ stretching indicating the strong H-interactions. The correlations of theoretical (DFT-B3LYP/aug-cc-pVDZ) and experimental UV-vis absorption spectra in neutral and alkaline ethanolic solutions showed the existence of hydroxyimino-nitroso tautomerism while ionization of I.
\end{abstract}

Keywords: Sodium 3,5-Bis(Hydroxyimino)-1-Methyl-2,4,6-Trioxocyclohexanide; Crystal Structure; IR Spectra; Electronic Absorption Spectra; Quantum Chemical Modeling

\section{Introduction}

2,4,6-Trihydroxytoluene (methylphloroglucinol, MPG) possesses strong and attractive synthetic potential because of its specific structure. However, till recent years when the economically efficient method of synthesis of MPG on base of 2,4,6-trinitrotoluene [1,2] was developed, it practically has not been realized.

The reactions of electrophilic substitution of H-atoms in the benzene ring of methylphloroglucinol have been poorly studied till now. Except one paper concerning its bromination [3], a series of ancient publications on MPG acylation by $\mathrm{HCN}$ and nitriles [4-8], or ethanoil chloride [6] and anhydride [8] are known. And there is the only one example of MPG alkylation by formaldehyde in presence of sulfuric acid [9].

In frames of systematic investigations, some reactions of MPG electrophylic substitution (bromination, sulfation, Hoesch reaction, azo-coupling) were recently reported [10-13]. As it was shown, in all cases except azo- coupling irrespectively of variations of reaction conditions mixtures of mono- and bis-substituted products were formed. In case of the reaction of MPG azo-coupling, nonstandard conditions were found which allowed selective synthesis of mono- and bis azo-compounds based on MPG.

In the present paper, we report the crystal structure, tautomerism, and some spectral characteristics of the product of the reaction of MPG nitrosation.

\section{Experimental}

\subsection{Synthesis of the Title Compound}

The title compound was prepared by the reaction of methylphloroglucinol (MPG) with sodium nitrite. $5 \mathrm{~g}$ of MPG (0.0357 mole) were dissolved in $50 \mathrm{ml}$ of water at $0^{\circ} \mathrm{C}$. The solution containing $6.41 \mathrm{~g}$ of $\mathrm{NaNO}_{2}(0.09$ mole) in $25 \mathrm{ml}$ of water was added with an intensive stirring. The solution was stored under $0^{\circ} \mathrm{C}$ for $40 \mathrm{~min}$, and then $0.7 \mathrm{ml}$ of $\mathrm{H}_{2} \mathrm{SO}_{4}$ in $28 \mathrm{ml}$ of water were added drop 
wise. After $30 \mathrm{~min}$ the formed precipitate was filtered off and dried over $\mathrm{P}_{2} \mathrm{O}_{5}$. The product was finally purified by re-crystallization. Yield $82 \%$ M.p. $208^{\circ} \mathrm{C}$ (with decomposition). The authenticity of the compound has been established by microanalyses, UV and IR spectra, and single crystal X-ray diffraction analysis.

\subsection{Materials and Physical Measurements}

The melting point was determined on an Electrothermal Model 9200 apparatus and is uncorrected. The IR absorption spectrum was obtained in the region of $400-4000$ $\mathrm{cm}^{-1}$ with a resolution of $4 \mathrm{~cm}^{-1}$ as $\mathrm{KBr}$ pellet using a Varian Excalibur HE 3100 IR spectrometer. Microanalysis was performed with a Carlo Erba Elemental Analyzer, model 1108. UV-vis spectrum was recorded in the range of $200 \mathrm{~nm}$ to $800 \mathrm{~nm}$ using a Varian Cary 50 Scan spectrophotometer. Calculations of ionization constants were performed according to the procedure described in [14].

\subsection{The X-Ray Crystallography}

For the crystal structure determination, the single-crystal of the compound I was used for data collection on an Enraf-Nonius CAD-4 diffractometer. The $\beta$-filtered Mo $\mathrm{K} \alpha$ radiation $(\lambda=0.71073 \AA)$ and an $\omega-2 \theta$ scan were used fordata collection. The lattice parameters were determined using reflections in the range $22<2 \theta<26^{\circ}$. The structure was solved with direct methods using SHELXS-93 [15]. The refinement of the structure was performed by the full-matrix least square method on F2 for all the data with anisotropic thermal parameters for non-hydrogen atoms. CCDC reference number 865,395. The supplementary crystallographic data can be obtained free of charge from the Cambridge Crystallographic Data Centre via www.ccdc.cam.ac.uk/data_request/cif. Molecular structure of the compound showing the atomic numbering scheme is shown in Figure 1. The crystallography details for the structures determination of the compound were presented in Table 1. Selected bond distances and bond angles are listed in Table 2.

\subsection{Quantum-Chemical Modeling}

The geometry optimization of isomers was performed by means of DFT-B3LYP/aug-cc-pVDZ approach. Electronic absorption spectra were predicted using TDDFT approach at the same theory level as geometry optimization. In TDDFT calculations, the bulk solvent effects were taken into account by means of polarizable continuum model (PCM). All calculations have been executed using the "SKIF-Chebyshev" supercomputer of the Moscow State University with FireFly package available free at http://classic.chem.msu.su/gran/firefly/index.html.

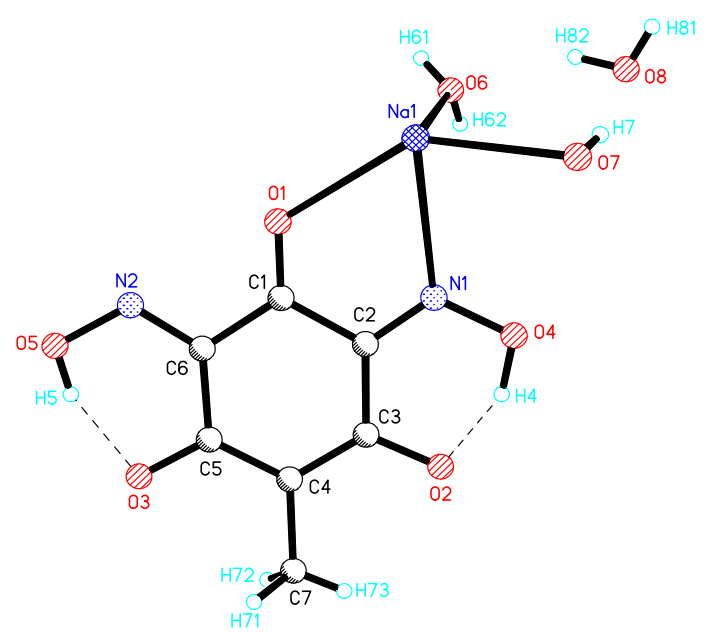

Figure 1. Molecular structure of I (O7-H7 represents 0.5 $\mathrm{H}_{2} \mathrm{O}$ ).

Table 1. Crystallographic data and structure refinement parameters.

\begin{tabular}{|c|c|}
\hline Empirical formula & $\mathrm{C}_{7} \mathrm{H}_{10} \mathrm{~N}_{2} \mathrm{NaO}_{7.5}$ \\
\hline Formula weight & $265.16 \mathrm{~g} / \mathrm{mol}$ \\
\hline Crystal color & Dark red \\
\hline Temperature & 293(2) K \\
\hline Wavelength & $0.71073 \AA$ \\
\hline Crystal system & Monoclinic \\
\hline Space group & $\mathrm{C} 2 / \mathrm{c}$ \\
\hline Unit cell dimensions & $\begin{array}{c}a=16.408(3) \AA, b=12.446(3) \AA, c= \\
13.716(3) \AA, \beta=126.34(3)^{\circ}\end{array}$ \\
\hline Volume & $2256.1(8) \AA^{3}$ \\
\hline$Z$, calculated density & $8,1.561 \mathrm{Mg} \cdot \mathrm{m}^{-3}$ \\
\hline Absorption coefficient & $0.172 \mathrm{~mm}^{-1}$ \\
\hline$F(000)$ & 1096 \\
\hline Crystal size & $0.50 \times 0.30 \times 0.20 \mathrm{~mm}$ \\
\hline Theta range for data collection & 2.25 to $25.47 \mathrm{deg}$. \\
\hline Limiting indices & $-19 \leq h \leq 15,0 \leq k \leq 14,-16 \leq l \leq 15$ \\
\hline Reflections collected/unique & $2191 / 2100[R($ int $)=0.0147]$ \\
\hline Completeness to theta $=25.47$ & $100 \%$ \\
\hline Refinement method & Full-matrix least-squares on F2 \\
\hline Data/restraints/parameters & $2100 / 0 / 200$ \\
\hline Goodness-of-fit on F2 & 1.056 \\
\hline Final $R$ indices $[\mathrm{I}>2$ sigma (I)] & $\mathrm{R} 1=0.0280, \mathrm{wR} 2=0.0868$ \\
\hline$R$ indices (all data) & $\mathrm{R} 1=0.1160, \mathrm{wR} 2=0.1005$ \\
\hline Largest diff. peak and hole & $0.281 \mathrm{e} \cdot \AA^{-3}$ and $-0.294 \mathrm{e} \cdot \AA^{-3}$ \\
\hline
\end{tabular}


Table 2. Selected bond lengths $(\AA)$ and angles $\left({ }^{\circ}\right)$.

\begin{tabular}{|c|c|c|c|}
\hline $\mathrm{O}(1)-\mathrm{C}(1)$ & $1.220(2)$ & $\mathrm{C}(2)-\mathrm{N}(1)-\mathrm{O}(4)$ & $117.52(14)$ \\
\hline $\mathrm{O}(2)-\mathrm{C}(3)$ & $1.271(2)$ & $\mathrm{C}(6)-\mathrm{N}(2)-\mathrm{O}(5)$ & $118.20(15)$ \\
\hline $\mathrm{O}(3)-\mathrm{C}(5)$ & $1.265(2)$ & $\mathrm{O}(1)-\mathrm{C}(1)-\mathrm{C}(6)$ & $122.54(15)$ \\
\hline $\mathrm{O}(4)-\mathrm{N}(1)$ & $1.3583(19)$ & $\mathrm{O}(1)-\mathrm{C}(1)-\mathrm{C}(2)$ & $121.51(15)$ \\
\hline $\mathrm{O}(5)-\mathrm{N}(2)$ & $1.348(2)$ & $C(6)-C(1)-C(2)$ & $115.95(13)$ \\
\hline $\mathrm{N}(1)-\mathrm{C}(2)$ & $1.293(2)$ & $\mathrm{N}(1)-\mathrm{C}(2)-\mathrm{C}(3)$ & $125.73(15)$ \\
\hline $\mathrm{N}(2)-\mathrm{C}(6)$ & $1.292(2)$ & $\mathrm{N}(1)-\mathrm{C}(2)-\mathrm{C}(1)$ & $113.70(14)$ \\
\hline$C(1)-C(6)$ & $1.471(2)$ & $C(3)-C(2)-C(1)$ & $120.43(14)$ \\
\hline$C(1)-C(2)$ & $1.483(2)$ & $\mathrm{O}(2)-\mathrm{C}(3)-\mathrm{C}(4)$ & $123.67(15)$ \\
\hline$C(2)-C(3)$ & $1.481(2)$ & $\mathrm{O}(2)-\mathrm{C}(3)-\mathrm{C}(2)$ & $115.34(15)$ \\
\hline$C(3)-C(4)$ & $1.395(3)$ & $\mathrm{C}(4)-\mathrm{C}(3)-\mathrm{C}(2)$ & $120.98(15)$ \\
\hline$C(4)-C(5)$ & $1.398(3)$ & $C(3)-C(4)-C(5)$ & $120.86(15)$ \\
\hline $\mathrm{C}(4)-\mathrm{C}(7)$ & $1.503(2)$ & $C(3)-C(4)-C(7)$ & $119.62(18)$ \\
\hline \multirow[t]{7}{*}{$C(5)-C(6)$} & $1.482(2)$ & $C(5)-C(4)-C(7)$ & $119.52(18)$ \\
\hline & & $\mathrm{O}(3)-\mathrm{C}(5)-\mathrm{C}(4)$ & $123.19(16)$ \\
\hline & & $\mathrm{O}(3)-\mathrm{C}(5)-\mathrm{C}(6)$ & $115.84(16)$ \\
\hline & & $\mathrm{C}(4)-\mathrm{C}(5)-\mathrm{C}(6)$ & $120.97(15)$ \\
\hline & & $\mathrm{N}(2)-\mathrm{C}(6)-\mathrm{C}(1)$ & $113.49(14)$ \\
\hline & & $\mathrm{N}(2)-\mathrm{C}(6)-\mathrm{C}(5)$ & $125.84(15)$ \\
\hline & & $C(1)-C(6)-C(5)$ & $120.62(15)$ \\
\hline
\end{tabular}

\section{Results and Discussion}

Dark-red plates of single crystals of the only product of MPG nitrosation were obtained by re-crystallization from ethanolic aqueous solution, and the crystal structure was determined by X-ray diffraction studies. The title compound crystallizes in a hydrated form of a sodium salt $\left(\mathrm{C}_{7} \mathrm{H}_{5} \mathrm{~N}_{2} \mathrm{NaO}_{5} \cdot 2.5 \mathrm{H}_{2} \mathrm{O}\right)$ in the monoclinic space group $\mathrm{C} 2 / \mathrm{c}$ with $Z=1$.

As it is evident (Figure 1, Table 2), the isolated product of transformation of MPG exists in the anionic form of a triketo-dihydroxyimino tautomer. The negative charge of the anion is neutralized by $\mathrm{Na}^{+}$cations. The $\mathrm{C}-\mathrm{O}$ distances in the planar organic anion (1.220(2); 1.271(2) and 1.265(2) $\AA$ for $\mathrm{C} 1-\mathrm{O} 1, \mathrm{C} 3-\mathrm{O} 2$ and $\mathrm{C} 5-\mathrm{O} 3$ respectively) as well as N1-C2 (1.293(2) $\AA$ ) and N2-C6 (1.292(2) $\AA$ ) are close to the corresponding double bonds. The $\mathrm{C}-\mathrm{C}$ bonds of the ring are not equivalent: $\mathrm{C} 1-\mathrm{C} 6$, $\mathrm{C} 1-\mathrm{C} 2, \mathrm{C} 2-\mathrm{C} 3$, and $\mathrm{C} 5-\mathrm{C} 6$ bond lengths (1.471(2) $1.483(2) \AA$ ) indicate a small degree of conjunction as

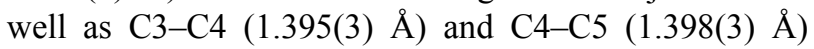
bonds are much shorter. Similar types of structures of polyketo-compounds of carbocyclic and heterocyclic series were reviewed in [16].

$\mathrm{H} 4$ and $\mathrm{H} 5$ atoms are located at $\mathrm{O} 4$ and $\mathrm{O} 5$ atoms of two hydroxyimino-groups of the anion and involved in the intramolecular H-bonds with the neighboring carbonyl O-atoms (Table 3).
The organic anion chelates the $\mathrm{Na}^{+}$cations by the oxygen atoms of $\mathrm{C}=\mathrm{O}$ groups and $\mathrm{N}$-atoms of neighboring oxime fragments $\left(r \mathrm{O}_{1} \mathrm{Na}-25,647(15) \AA ; r \mathrm{~N} \mathrm{~N}_{1} \mathrm{Na}\right.$ $-26,625(16) \AA)$. The $\mathrm{O}(1), \mathrm{N}(2)$ atoms as well as the O-atoms of both oxime groups are also involved in coordination with the $\mathrm{Na}^{+}$cations of the neighboring molecules. The coordination sphere of $\mathrm{Na}^{+}$also includes two water molecules, one of which is bridging. One of $\mathrm{H}_{2} \mathrm{O}$ molecules is of the lattice nature. Thus, a 3D lattice is formed (Figure 2) which is linked by intermolecular H-bonds involving coordinated and lattice water molecules (Table 3).

The organic anion chelates the $\mathrm{Na}^{+}$cations by the oxygen atoms of $\mathrm{C}=\mathrm{O}$ groups and $\mathrm{N}$-atoms of neighboring oxime fragments $\left(r \mathrm{O}_{1} \mathrm{Na}-25,647(15) \AA ; r \mathrm{~N}_{1} \mathrm{Na}\right.$ $-26,625(16) \AA)$. The $\mathrm{O}(1), \mathrm{N}(2)$ atoms as well as the O-atoms of both oxime groups are also involved in coordination with the $\mathrm{Na}^{+}$cations of the neighboring molecules. The coordination sphere of $\mathrm{Na}^{+}$also includes two water molecules, one of which is bridging. One of $\mathrm{H}_{2} \mathrm{O}$ molecules is of the lattice nature. Thus, a 3D lattice is formed (Figure 2) which is linked by intermolecular $\mathrm{H}$-bonds involving coordinated and lattice water molecules (Table 3).

Table 3. Hydrogen bonds in I ( $\AA$ and deg.).

\begin{tabular}{ccccc}
\hline $\mathrm{D}-\mathrm{H} \ldots \mathrm{A}$ & $\mathrm{d}(\mathrm{D}-\mathrm{H})$ & $\mathrm{d}(\mathrm{H} \ldots \mathrm{A})$ & $\mathrm{d}(\mathrm{D} \ldots \mathrm{A})$ & $<(\mathrm{DHA})$ \\
\hline $\mathrm{O}(4)-\mathrm{H}(4) \ldots \mathrm{O}(2)^{\#} 1$ & $1.06(3)$ & $1.46(3)$ & $2.442(2)$ & $151(3)$ \\
$\mathrm{O}(5)-\mathrm{H}(5) \ldots \mathrm{O}(3)^{\#} 1$ & $0.81(3)$ & $1.69(3)$ & $2.470(2)$ & $161(3)$ \\
$\mathrm{O}(7)-\mathrm{H}(7) \ldots \mathrm{O}(8)^{\#} 1$ & $0.83(3)$ & $1.98(3)$ & $2.797(2)$ & $165(3)$ \\
$\mathrm{O}(6)-\mathrm{H}(61) \ldots \mathrm{O}(2)^{\#} 4$ & $0.76(3)$ & $2.03(3)$ & $2.748(2)$ & $158(3)$ \\
$\mathrm{O}(6)-\mathrm{H}(62) \ldots \mathrm{O}(8)^{\#} 5$ & $0.88(5)$ & $1.86(5)$ & $2.732(2)$ & $169(4)$ \\
$\mathrm{O}(8)-\mathrm{H}(81) \ldots \mathrm{O}(3)^{\#} 6$ & $0.77(4)$ & $2.01(4)$ & $2.763(2)$ & $170(3)$ \\
$\mathrm{O}(8)-\mathrm{H}(82) \ldots \mathrm{O}(6)^{\#} 1$ & $0.82(4)$ & $2.01(4)$ & $2.737(2)$ & $147(4)$ \\
\hline
\end{tabular}

Symmetry transformations used to generate equivalent atoms: ${ }^{\#} 1 \mathrm{x}, \mathrm{y}, \mathrm{z}{ }^{{ }^{*}} 2$ $-\mathrm{x}+1,-\mathrm{y}+1,-\mathrm{z} \# 3-\mathrm{x}+1, \mathrm{y},-\mathrm{z}+1 / 2^{\#} 4 \mathrm{x},-\mathrm{y}+1, \mathrm{z}-1 / 2{ }^{\#} 5-\mathrm{x}+1 / 2,-\mathrm{y}+1 / 2$, $-\mathrm{z}^{\#} 6 \mathrm{x}, \mathrm{y}-1, \mathrm{z}$.

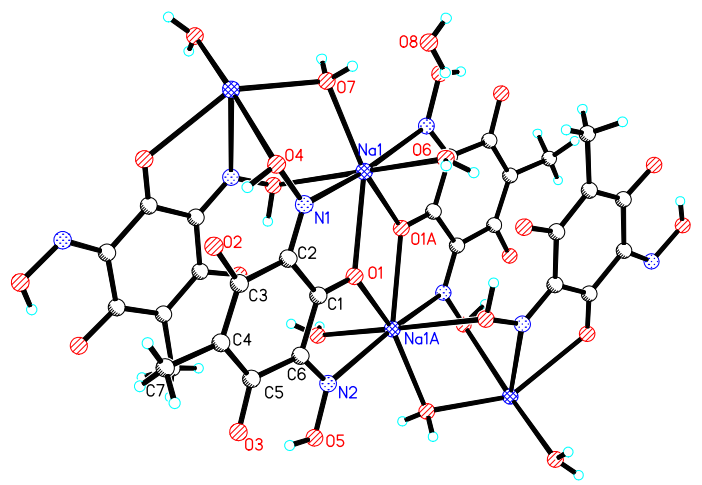

Figure 2. Fragment of the crystal structure of I. 
Elemental analyses of the compound I for carbon, hydrogen, and nitrogen are in good agreement with theoretical values. The theoretical and observed element percentages respectively are: $\% \mathrm{C}: 32.07$ and $31.71, \% \mathrm{H}$ : 3.65 and $3.80, \% \mathrm{~N}: 10.24$ and 10.56 .

The IR spectrum of the title compound shows sharp characteristic absorption bands at $1681 / 1645 \mathrm{~cm}^{-1}$ due to $\mathrm{C}=\mathrm{O}$ stretching mode of the keto-groups which are involved into strong $\mathrm{H}$-interactions. The wide absorption band in the interval $3550-3300 \mathrm{~cm}^{-1}$ with two maxima at 3460 and $3380 \mathrm{~cm}^{-1}$ are $\mathrm{r}(\mathrm{CO})$ vibrations of $\mathrm{OH}$ groups of $\mathrm{NOH}$ fragments and water molecules [17]. The sharp skeleton bands observed at $1580(\mathrm{w}), 1520(\mathrm{~s})$ and 1510 (m) $\mathrm{cm}^{-1}$ characterize the $\mathrm{C} \ldots \mathrm{C}$ and $\mathrm{C} \ldots \mathrm{N}$ vibrations.

The electronic absorption spectrum of I (Figure 3) is characterized by two absorption bands at $273.42 \mathrm{~nm}$ $(\log \varepsilon 4.03)$ and $380.55 \mathrm{~nm}(\log \varepsilon 3.83)$. The addition of $\mathrm{HCl}$ till $\mathrm{pH} 1$ does not provoke any changes in the spectrum. This may indicate the stability of anionic form of the organic species in I. In alkaline solutions, the absorption bands collapse, and an intensive absorbance at $329.08 \mathrm{~nm}(\log \varepsilon 4.25)$ appears.

In order to explain the changes in the UV-Vis spectra recorded at different $\mathrm{pH}$ values, quantum chemical calculations of electronic absorption spectra of ethanolic solutions of the most stable neutral dihydroxyimino- and dinitroso-tautomers as well as their anionic forms (Figure 4) were performed by the TDDFT method.

The calculated UV spectrum of the neutral dixydroxyimino-form is characterized by an absorption band at $354.79 \mathrm{~nm}(f$ 0.056) and an intensive doublet $280.89(f$ 0.383 ), and 265.62 ( $f$ 0.284) $\mathrm{nm}$ (Figure 5(a)). In a dihydroxyimino monoanionic form the bands are increased in intensity and shifted to 369.36 ( $f$ 0.130) and271.48 ( $f 0.513) \mathrm{nm}$ (Figure 5(c)). The shape of the spectrum and relative intensities of the absorption bands are in a good accordance of the experimental spectrum of I in neutral solutions.

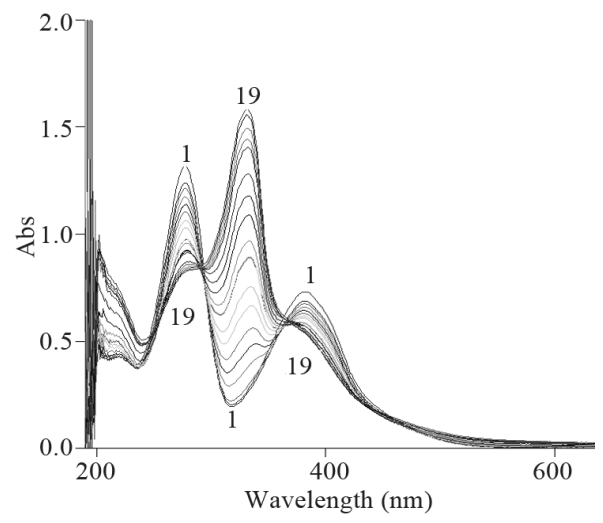

Figure 3. Experimental electronic absorption spectra of ethanol solutions of $I$ in the $\mathrm{pH}$ range between 6.0 (curve 1) and 11.0 (curve 19).

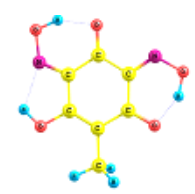

(a)

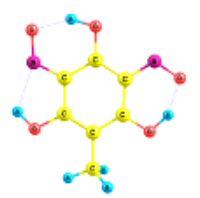

(b)

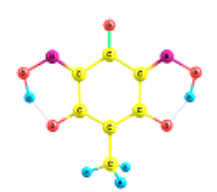

(c)

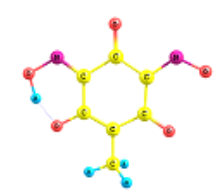

(d)

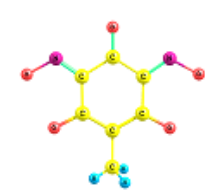

(e)
Figure 4. Optimized geometries of the neutral dihydroxyimino (a), dinitrozo (b) tautomers of I and its mono- (c), di- (d) and trianionic (e) forms.

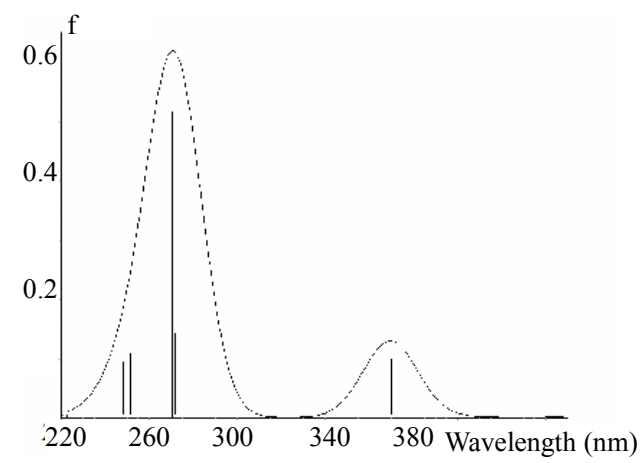

(a)

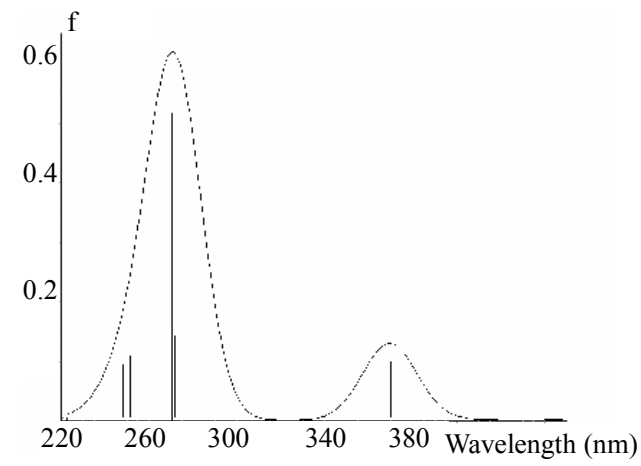

(c)

Figure 5. Calculated UV-Vis spectra of the dihydroxyimino tautomer of $I$ in a neutral (a) and monoanionic (c) forms.

The calculated spectrum of the neutral dinitrozotautomer of I can be characterized by a strong absorption due to imposing of two transitions at $296.76(f 0.220)$ and 288.38 ( $f 0.522) \mathrm{nm}$ (Figure 6(b)). In the spectrum of the trianionic form only one strong absorbance occurs at $297.21 \mathrm{~nm}(f$ 0.518) (Figure 6(e)). The calculated spectrum of the dianionic form is much more complicated and consists of transitions at 376.31 ( $f$ 0.043), 310.74 ( $f 0.285), 303.23$ ( $f 0.138), 277.32$ ( $f 0.153)$, and 266.73 ( $f$ 0.032) nm (Figure 7). The imposing of these transitions should lead to the appearance of a wide absorption band or a set of absorption bands. This fact 


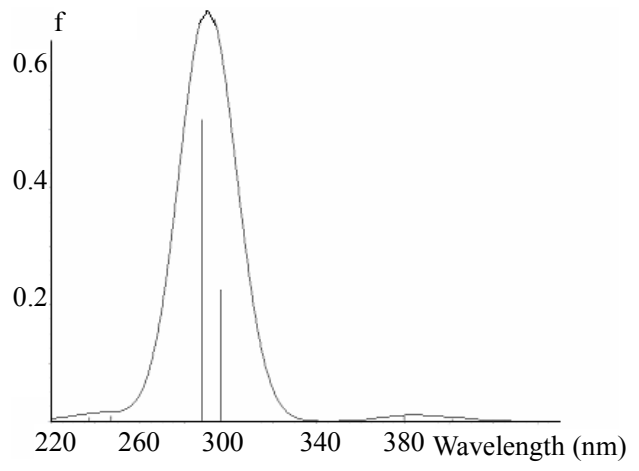

(b)

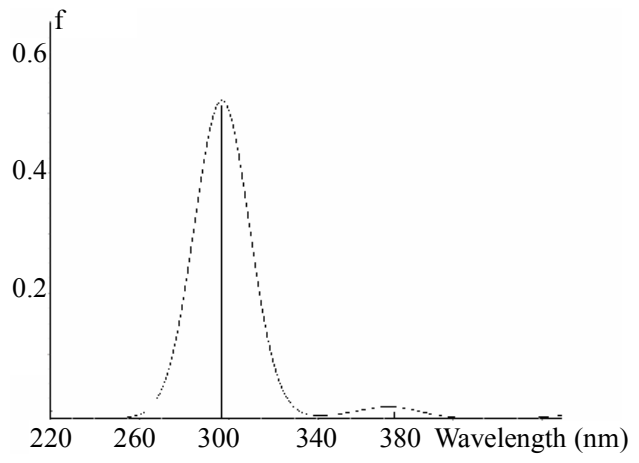

(e)

Figure 6. Calculated UV-Vis spectra of the dinitrozo neutral tautomer of $I$ (b) and its trianionic (e) form.
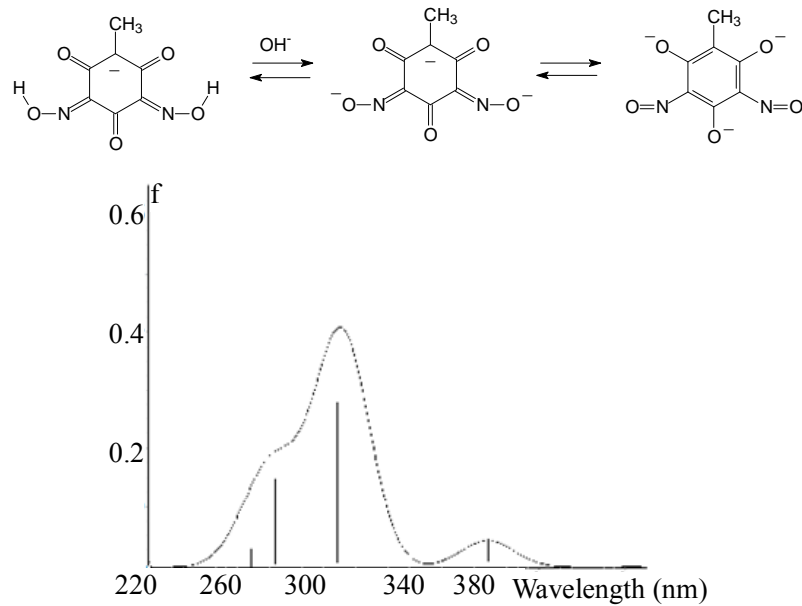

Figure 7. Calculated UV-Vis spectrum of the dianionic form of $\mathbf{I}$.

contradicts with the shape of the experimental spectrum of $I$ in alkaline solutions where a sharp intensive absorption occurs at $329.08 \mathrm{~nm}(\log \varepsilon 4.25)$.

Thus, it is possible to conclude that the dihydroxyimino-isomer is more preferable in the crystalline form and neutral solutions. The process of ionization is accompanied by its tautomeric transformation into the dinitroso-form:
Basing on the results of the spectrophotometric titration of I, the ionization constant of the oxime groups was calculated to be $\mathrm{pK} 7.55 \pm 0.42$. The calculated value correlates with the corresponding literature data for other cyclic oximes [18].

\section{Conclusion}

Consequently, the novel compound is obtained by the reaction of nitrosation of methylphloroglucinol. According to the single crystal X-ray diffraction data, it exists in the anionic form as sodium 3,5-bis(hydroxyl-imino)-1methyl-2,4,6-trioxocyclohexanide. In the alkaline solutions, the further dissociation takes place which is accompanied by the transformation of the organic anion into the dinitrozo-tautomer.

\section{Acknowledgements}

The research has been executed under financial support of the Russian Foundation for Basic Researches (project 10-03-00003-a).

\section{REFERENCES}

[1] W. S. Atkins and J. Wilson, "Synthesis of Polynitrodiazophenols," The Journal of Organic Chemistry, Vol. 51, No. 13, 1986, pp. 2572-2578. doi:10.1021/jo00363a033

[2] S. A. Shevelev, A. Kh. Shakhnes, B. J. Ugrak and S. S. Vorob'ev, "Highly Selective One-Step Synthesis of 2Amino-4,6-Dinitrotoluene and 2,6-Diamino-4-Nitrotoluene from 2,4,6-Trinitrotoluene," Synthetic Communications, Vol. 37, No. 17, 2001, pp. 2557-2561. doi:10.1081/SCC-100105379

[3] J. Herzing, J. Pollak and K. Rohm, "Studien Über Die Halogenderivate der Phloroglucine," Monatshefte für Chemie-Chemical Monthly, Vol. 21, No. 6, 1900, pp. 498511. doi:10.1007/BF01525541

[4] F. H. Curd and A. Robertson, "Usnic Acid. Part I. Derivatives of Methylphloroglucinol," Journal of Chemical Society, 1933, pp. 437-444. doi:10.1039/jr9330000437

[5] H. Brockmann and K. Mayer, "Über das Rottlerin," Justus Liebigs Annalen der Chemie, Vol. 535, No. 1, 1938, pp. 149-175. doi:10.1002/jlac.19385350109

[6] F. H. Curd and A. Robertson, "Usnic Acid. Part II. Usneol," Journal of Chemical Society, 1933, pp. 714-720. doi:10.1039/jr9330000714

[7] F. M. Dean and A. Robertson, "Usnic Acid. Part VIII. C-Diacetyl Derivatives of Phloroglucinol and C-Methylphloroglucinol," Journal of Chemical Society, 1953, pp. 1241-1249. doi:10.1039/jr9530001241

[8] P. Karrer, "Über Oxycarbonylverbindungen II. Synthetische Versuche in der Filixgruppe," Helvetica Chimica Acta, Vol. 2, No. 1, 1919, pp. 466-481. doi:10.1002/hlca.19190020149 
[9] R. Boehm, "Ueber Methylenverbindungen in der Phloroglucinreihe," Justus Liebigs Annalen der Chemie, Vol. 329, 1903, pp. 269-301. doi:10.1002/jlac.19033290302

[10] V. Ushkarov, K. Kobrakov, A. Alafinov, G. Stankevich, S. Shevelev and A. Shakhnes, "Methyl Phlorogluci-nolBased Dyes for Chemical Fibres," Fibre Chemistry, Vol. 38, No. 2, 2006, pp. 188-190. doi:10.1007/s10692-006-0067-3

[11] V. I. Ushkarov, "Synthesis and Studies of Properties of Azo-Compound Based on Methylfloroglucinol," Ph.D. Thesis, Moscow State Textile University, Moscow, 2006.

[12] G. S. Stankevich, K. I. Kobrakov, O. V. Volyansky, O. V. Kovalchukova, V. I. Ushkarov, A. I. Alafinov, A. Kh. Shakhness, M. D. Dutov, S. A. Shevelev, P. V. Strashnov and E. P. Romashkina, "Trinitrotoluene as a Precursor in Synthesis of Effective Azodyes and Azopygments," Proceedings of the 13th Seminar on New Trends in Research of Energetic Materials. Part I, Pardubice, 21-23 April 2010, pp. 255-258.

[13] O. V. Kovalchukova, S. A. Shevelev, A. H. Shakhnes, K. K. Kobrakov, A. I. Alafinov, O. V. Volyansky and P. V. Strashnov, "Some Physico-Chemical Properties of Products of Chemical Transformation of 2,4,6-Trinitro- toluene," Proceedings of the 14th Seminar on New Trends in Research of Energetic Materials. Part I, Pardubice, 13-15 April 2011, pp. 264-268.

[14] J. Nagypal and M. T. Beck, "Rules Governing Concentration Distribution in Complex Equilibrium Systems," Journal of Chemical Society, Vol. 80, No. 7, 1980, pp. 722-726. doi:10.1021/j100444a008

[15] G. M. Sheldrick, "SHELXL 93. Program for the Refinement of Crystal Structures," University of Gottingen, 1993.

[16] O. Kovalchukova, S. Strashnova and B. Zaitsev, "Polyoxo-Compounds of Carbocyclic and Heterocyclic Series," LAP Lambert Academic Publishing GmbH \& Co., Saarbrücken, 2011.

[17] G. C. Bassler, T. C. Morrill and R. M. Silverstein, "Spectrometric Identification of Organic Compounds," Wiley, New York, 1991.

[18] A. I. Mikhaleva, A. B. Zaitsev and B. A. Trofimov, "Oximes as Reagents," Russian Chemical Reviews, Vol. 75, No. 9, 2006, pp. 797-823. doi:10.1070/RC2006v075n09ABEH003594 